\title{
Barrier-free urban environment and risks of project solutions implementation
}

\author{
Vladimir Rimshin ${ }^{1}$, Victoria Borkovskaya ${ }^{2}$, Evgeniy Degaev ${ }^{3,}$, and Igor Shubin ${ }^{3}$ \\ ${ }^{1}$ Moscow State University of Civil Engineering, Yaroslavskoe shosse 26, Moscow, 129337, Russia \\ ${ }^{2}$ Plekhanov Russian University of Economics, Stremyanny Lane, 36, Moscow, 117997, Russia \\ ${ }^{3}$ Research Institute of Building Physics, Lokomotivny pr. 21, Moscow, 127238, Russia
}

\begin{abstract}
The article presents the legislative and regulatory framework that guarantees the right to an accessible environment, highlights the practical issues of creating a barrier-free environment for various groups of people with disabilities. The current standards that establish the main requirements for the implementation of project solutions aimed at the free movement of disabled people and other low-mobility groups in the urban environment are analyzed.
\end{abstract}

\section{Introduction}

One of the objectively difficult problems that people with disabilities have to face when exercising their rights to health care, social protection, education, work, and leisure is the problem of ensuring unhindered access to engineering, transport, social, and information infrastructure. The inability to move independently in the modern urban space, and the unavailability of disabled people to visit socially significant institutions (schools, hospitals, and cultural institutions) significantly complicates the lives of people with disabilities.

Ensuring an accessible environment for people with limited mobility is one of the priorities of modern state policy. The UN Convention on the rights of persons with disabilities has been ratified, the state program "Accessible environment" is being implemented, and new administrative and technical regulations are being introduced.

However, the implementation of these standards in the implementation of specific works to create a barrier-free environment for disabled people and other low-mobility groups of citizens, including within the framework of the state program "Accessible environment", faces a number of objective difficulties. Today, not all specialists of state and municipal institutions-direct executors of the program-are familiar with the peculiarities of organizing a barrier-free environment in priority areas of life for disabled people. They do not always know the specific features of different disability groups, and they have no practical experience in adapting specific socially significant objects.

As a result of this state of Affairs - often a formal approach to ensuring the accessibility of the environment by the heads of organizations, institutions and enterprises; government initiatives remain categories of law, not finding their reflection in real life; inefficient

*Corresponding author: degaev@inbox.ru 
spending of funds; the inability to use already adapted facilities for disabled people and other low-mobility groups of the population.

The purpose of this work is to study the theoretical and practical aspects of organizing a barrier-free environment for the disabled and other low-mobility groups of the population, as well as to analyze the risks of implementing project solutions [1-5].

\section{Materials and methods}

Currently, in Russia, the share of people with limited mobility is up to $41 \%$ (58 million people) of the total population of the country, including: $10.7 \%$ - disabled people of all ages; $16.3 \%$ - elderly people (older than able-bodied) who are not recognized as disabled; $6.2 \%$ - people with temporary disability, with Luggage, other groups of the population with mobility restrictions; $7.7 \%$ - children under the age of 4 years (about 8 million people, including accompanied by one adult of working age - about 3 million people).

Federal law No. 181-FZ "on social protection of disabled people in the Russian Federation"is the main law that guarantees the rights of disabled people and people with limited mobility in the Russian Federation, including the right to an accessible environment. This Federal law defines the state policy in the field of social protection of invalids in the Russian Federation, the purpose of which is to ensure disabled people equal opportunities in realization of civil, economic, political and other rights and freedoms. Taking into account a number of changes and additions made by Federal law No. 419 "on amendments to certain legislative acts of the Russian Federation on social protection of disabled people", the responsibilities of government bodies, local self-government and other organizations in addressing accessibility issues have significantly expanded.

According to Article 15 "ensuring unhindered access of disabled people to social, engineering and transport infrastructure facilities", Federal state authorities, state authorities of the subjects of the Russian Federation, local self-government bodies (in the sphere of established powers), organizations, regardless of their organizational and legal forms, provide disabled people (including people with disabilities who use wheelchairs and guide dogs):

1) conditions for unhindered access to social, engineering, and transport infrastructure (residential, public, and industrial buildings, structures, and structures, including those where sports organizations, cultural organizations, and other organizations are located), recreation facilities, and services provided there;

2) conditions for unhindered use of railway, air, water transport, road transport and urban ground electric transport in urban, suburban, intercity communication, communication and information means (including means that ensure the duplication of sound signals of traffic lights and devices that regulate the movement of pedestrians through transport communications);

3) the possibility of independent movement on the territory where the objects of social, engineering and transport infrastructure are located, entering and exiting such objects, boarding and disembarking from a vehicle, including using a wheelchair;

4) accompanying disabled people with persistent visual impairment and independent movement, and providing them with assistance at social, engineering and transport infrastructure facilities;

5) proper placement of equipment and information carriers necessary to ensure unhindered access of persons with disabilities to social, engineering and transport infrastructure facilities and services, taking into account the limitations of their life activities; 
6) duplication of sound and visual information necessary for disabled people, as well as inscriptions, signs and other text and graphic information with signs made in relief and dot Braille, the admission of a sign language interpreter and a tiflosurd interpreter;

7) admission to objects of social, engineering and transport infrastructure of the guide $\operatorname{dog}$ in the presence of a document confirming its special training;

8) providing employees of organizations that provide services to the population with assistance to people with disabilities in overcoming barriers that prevent them from receiving services on an equal basis with other persons.

"Urban planning code of the Russian Federation" of 29.12.2004 No. 190-FZ regulates relations on territorial planning, urban zoning, territory planning, architectural and construction design, relations on construction of capital construction objects, their reconstruction, capital repairs, during which the structural and other characteristics of reliability and safety of such objects are affected, and also defines the basic principles of legislation on urban development (article 2). Among these principles, it is worth highlighting: providing disabled people with conditions for unhindered access to social and other facilities.

In order to make the facility and its services fully accessible to people with disabilities and other MGNS, four types of barriers must be removed: physical, informational, organizational, and communicative. The removal of each of these barriers is more or less important for a particular category of IHL, depending on the specific needs and type of restrictions. Architectural solutions of public buildings and structures are recommended to focus simultaneously on compensation of health disorders in the field of the musculoskeletal system, hearing, vision, and psyche. Depending on the type of physical and sensory limitations, different approaches to creating a barrier-free environment are required. It is necessary to know well the specific features of different categories of disabled people and how to provide them with conditions for compensating for life restrictions.

People with disabilities with disorders of the musculoskeletal system differ significantly from other people in their anthropometric and ergonometric characteristics. They require wider spaces for movement and maneuvering, need flat vertical surfaces, have difficulties in movement and need support devices, have difficulty overcoming various vertical obstacles in the form of stairs, thresholds, it is difficult for them to use ordinary furniture and equipment.

A specific feature of the blind and visually impaired is the fact that the main amount of information a person perceives visually, and it becomes obvious that the main problem of the blind and visually impaired is not a complete perception of the world around them. In many cases, due to the lack of an accessible environment, people with visual disabilities are at serious risk on the streets of our cities. But almost all problems of this nature can be avoided by creating some conditions that could compensate for the lack of vision.

It is important to note that the accessible environment for the visually impaired is not only all sorts of devices and tools created specifically for the blind and visually impaired, but also quite ordinary, but correctly made elements of the environment (stairs, sidewalks, etc.). It should be emphasized that the organization of an accessible environment for people with visual disabilities is less expensive, in contrast, for example, to the environment necessary for people who move using a wheelchair. It does not require major changes (reconstruction of buildings, construction of ramps), but includes the reconstruction of some elements of the environment that are useful not only for the blind, but also for all people (handrails, steps), and only minor additions (tactile pointers, contrasting lines, signatures in relief and dot Braille, a sound beacon, etc.).

The same can be said for people who are deaf or hard of hearing. They have difficulties in orientation and communication when receiving services, as well as in ensuring safety, 
that is, in obtaining timely information about a dangerous situation for this category of MGN, it is necessary to duplicate all the audio information in the form available to them (text, sign language translation) and use special sound amplification devices (induction loops, etc.) [4-6].

\section{Results and discussion}

\subsection{Pedestrian paths}

To ensure convenient and safe movement of all visitors to buildings and facilities, including people with limited mobility, from arrival at the facility to the entrance should be paid great attention to the layout and equipment of pedestrian traffic routes. For this purpose, the conditions for unhindered, safe and convenient movement of the MGN on the site to the accessible entrance to the building must be provided on a mandatory basis. These paths should connect with external transport and pedestrian communications, specialized Parking spaces, and public transport stops. When planning and organizing pedestrian routes in the surrounding area, it is recommended to pay special attention to the following points:

- provide landmarks along the route to help you find your way;

- landscaping elements and small architectural forms (lights, trash cans, flower pots, benches, etc.) should not be on the road;

- the height of the free space above pedestrian paths (under trees, canopies, brackets, etc.) must be at least $2.1 \mathrm{~m}$;

- in all places where the smooth change in the height level along the way is greater than the height equivalent to the height of one step, two alternative ways of overcoming the height difference should be provided, both using a ramp (for wheelchair users and other MGNS) and using steps, because it is much easier for many people to overcome a short flight of stairs than a ramp.

- the width of the pedestrian path, taking into account oncoming traffic of disabled people in wheelchairs, must be at least 2 meters (fig. 1). In terms of the existing development shall be allowed within line of sight to reduce the width of traffic path of 1.2 metres should be set no more than every $25 \mathrm{~m}$ horizontal area "pockets" of size not less than 1.8-2.0 $\mathrm{m}$ to allow separation of disabled people in the wheel chairs.
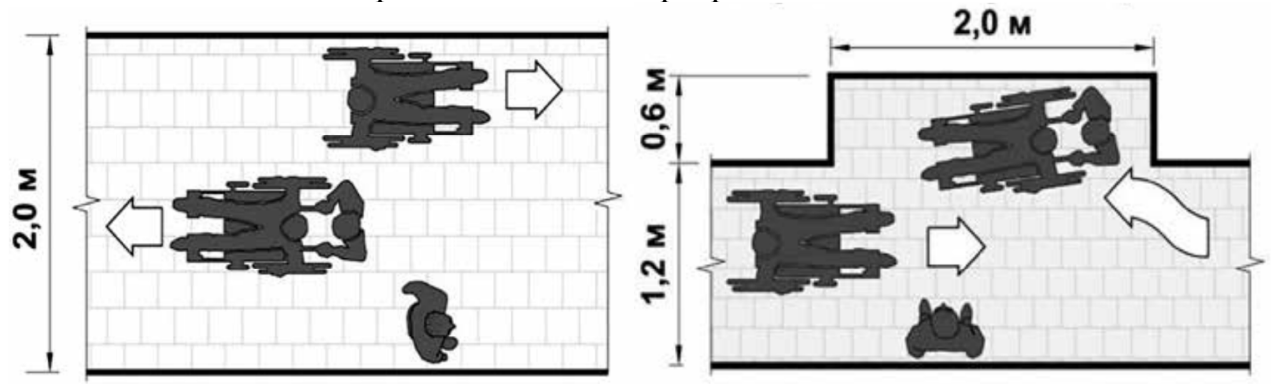

Fig. 1. The width of the traffic path on the section at oncoming traffic of disabled people and an example of the organization of a zone for oncoming traffic.

\subsection{Crossing the roadway}

Transport passages on the site and pedestrian paths to objects can be combined if the townplanning requirements for the parameters of traffic paths are met (fig. 2). In order to comply with these requirements, it is necessary to organize ground-based unregulated pedestrian 
crossings marked with markings in accordance with GOST R 51256 and road signs in accordance with GOST R 52290, as well as technical means of visual and/or tactile information.

For exits, their longitudinal slope should be no more than 1: $20(5 \%)$, near the building - no more than 1:12 (8\%), and in places characterized by cramped conditions - no more than 1:10 (10\%) for a maximum of $1.0 \mathrm{~m}$ (previously, near the building and in crowded places, it was allowed to increase the longitudinal slope to 1:10 for a maximum of $10 \mathrm{~m}$ ). That is, the slope of the Congress should be $5 \%$ (in cramped conditions, no more than 10 $\%)$. For example, if the height difference between the sidewalk and the roadway is $15 \mathrm{~cm}$, then the length of the ramp in normal conditions should be at least $3 \mathrm{~m}$. The length of the surface of the curb ramp is not recommended to make more than $6 \mathrm{~m}$. the slope of the ramp should be the same along its entire length. When climbing, it is not easy for a person in a wheelchair to overcome a curb of $1.5 \mathrm{~cm}$. and if they encounter a sharp ledge on the ramp (a short-term slope of more than $20 \%$ ), they may turn over backwards.

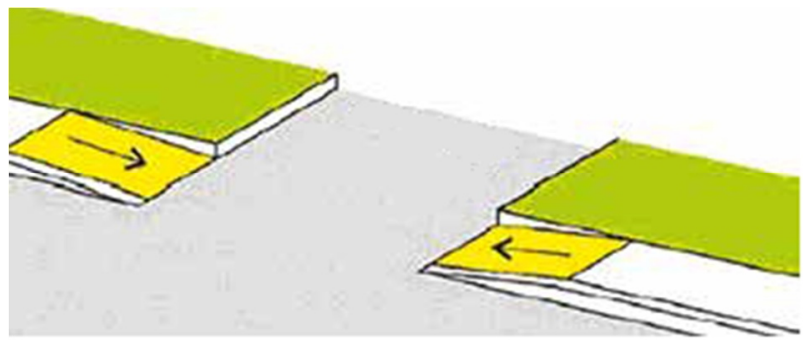

Fig. 2. A ramp designed to fit the width of a sidewalk or footpath.

\subsection{Disabled parking}

On the territory adjacent to a socially significant object, it is necessary to provide Parking spaces for vehicles. Special spaces should be allocated for vehicles with disabilities in Parking lots (fig. 3). According to the new version of SP 59.13300.2016, 10\% of Parking spaces (but not less than one space) for people with disabilities should be allocated in the Parking lot (Parking lot) of personal use vehicles located on the site near the building of the service sector organization or inside this building, including the number of specialized extended Parking spaces for vehicles with disabilities moving in a wheelchair, based on the number of seats:

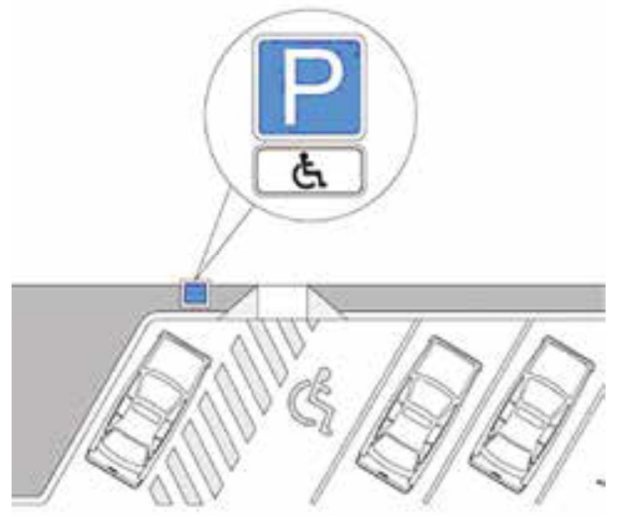

Fig. 3. Scheme for organizing a Parking space for the disabled. 


\subsection{Recreational area}

On the site of the object on the main routes of movement of people, it is recommended to provide at least 100-150 m of recreation areas available for MGN, equipped with canopies, benches, pay phones, signs, lamps, alarms, etc. recreation Areas should perform the functions of architectural accents included in the General information system of the object. Recreation areas should be located on a flat surface.

It is also necessary to install a trash can and provide a place for placing a wheelchair. Benches for the disabled, including the blind, are installed on the side of the aisles. But it is better to put benches in specially organized for this purpose "pockets" of sidewalks. Fig. 4 shows the main parameters of an outdoor chair (sofa) for the disabled.

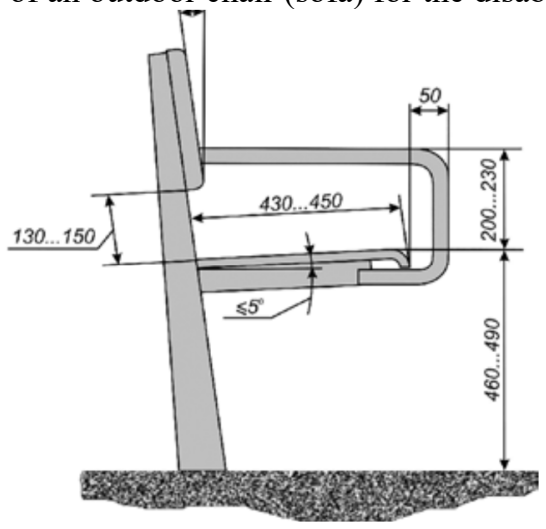

Fig. 4. The main parameters of the outdoor chair (sofa) for the disabled.

\subsection{Buildings and structures}

All buildings and structures that can be used by persons with disabilities must have at least one accessible entrance from the ground surface and from each underground or aboveground level accessible to the MHG connected to this building. If necessary, the entrance must be equipped with a staircase, ramp, or other device that allows the disabled and other MGNS to ascend to the entrance level of the building, its first floor, or Elevator hall.

When designing and constructing a ramp, keep in mind that a slope of less than $5 \%$ can be overcome by a person in a wheelchair on their own without support devices and assistance. A surface with a slope of $5 \%$ or more causes certain difficulties for a wheelchair user, so it is necessary to install handrails on both sides. If the slope is more than $8 \%$, many wheelchair users need the help of an accompanying person, because due to gender, age, and the nature of the disease, not everyone has enough strength to climb. (fig. 5 ) in Addition, most hand-operated wheelchairs are unstable during ascent and can tip over backwards, and when descending, the disabled person may fall out of the wheelchair when braking sharply on a small bump.

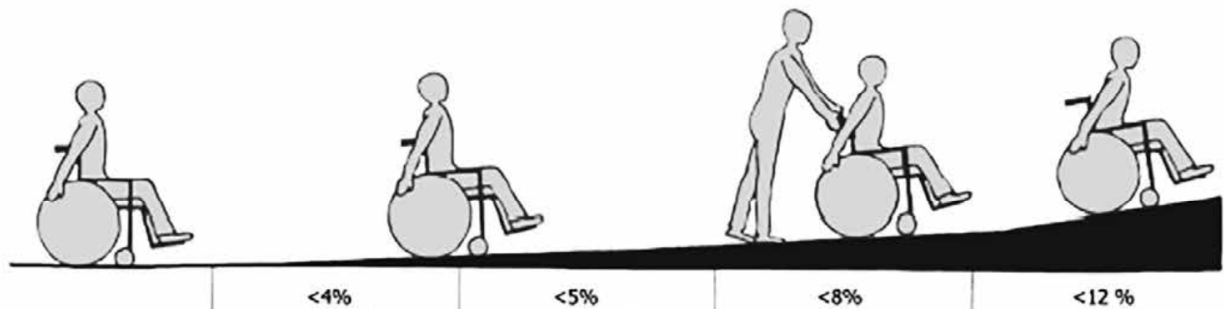

Fig. 5. Ramp slope characteristics. 
Fences with handrails must be installed along both sides of all ramps and open staircases, as well as at all height differences of horizontal surfaces greater than $0.45 \mathrm{~m}$

It is often mistakenly assumed that handrails should only be on stairs higher than 45 centimeters ( 3 steps) from the floor or sidewalk level. The height standard of $0.45 \mathrm{~m}$ does not apply to stairs, but to height differences, for example, to the entrance platform on the porch. If the height of the porch is more than 45 centimeters, then there should be fences along the edges of its horizontal part. This is required so that a person with limited mobility does not accidentally fall from the porch to the ground [7-9].

On the side, external to the March, the surface of the handrails of public buildings (except for hospitals) should be provided for relief designations of floors, as well as warning strips about the end of the railing. For the blind and visually impaired, the parts of the handrails that correspond to the first and last stages of the March should be marked with areas of surface with a pronounced fluting (tactile stripe) and a contrasting color (fig. 6).

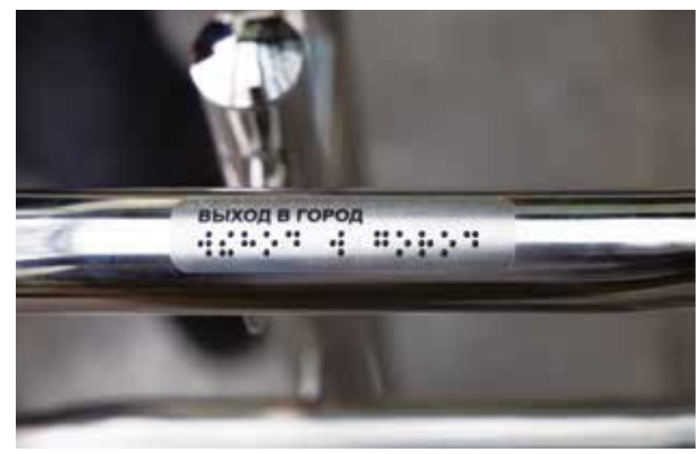

Fig. 6. Tactile information on the handrail.

\subsection{Identification of risks}

The nature of the "Accessible environment" Program generates a number of the following risks when it is implemented:

* lack of expected Program outcomes that improve the quality of life of people with disabilities and other low-mobility groups;

* non-relevance of planning and delay in coordination of activities related to technology development;

* passive resistance to the dissemination and use by public authorities of the results of the Program implementation;

* insufficient flexibility and adaptability of the Program to external factors and organizational changes of public authorities;

* duplication and inconsistency of actions in the implementation of activities under the Program;

* passive resistance of individual citizens and public organizations with disabilities in the framework of the Program's activities for ethical, moral, cultural and religious reasons.

The total probability of injury risk is defined as the product of events

$$
P=P S \cdot P s p \cdot P t r
$$

where $P$ - probability to suffer in overcoming element of a route, $R s$ - probability to suffer in independent movement, Since the probability to suffer when accompanied by Rivers - the probability of injury during the movement. 
Probabilities of Rs, Rsp, Ptr are determined by recording cases of injury during the year in the study area.

\section{Conclusions}

Management measures aimed at reducing the risks of implementing the "Accessible environment" Program include:

* strategic planning and forecasting. Program participants develop a long-term strategy to ensure the creation of conditions of accessibility for persons with disabilities and other disabled groups in the relevant areas of legal regulation and control of their execution;

* application of legal methods of influence (a set of normative legal acts of the Federal and regional levels) that contribute to the solution of the Program's tasks at all levels of Executive power;

* defining the organizational structure for managing the implementation of the Program (composition, functions, and consistency of links at all levels of management) [10-41].

\section{References}

1. V.G. Borkovskaya, E.N. Degaev, I. Burkova, MATEC Web of Conferences 193, 05027 (2018). DOI: https://doi.org/10.1051/matecconf/201819305027

2. V. Polyakova, E.N. Degaev, P.E. Haddad, MATEC Web of Conferences 251, 06017 (2018). DOI: https://doi.org/10.1051/matecconf/201825106017

3. E.N. Degaev, MATEC Web of Conferences 193, 02032 (2018). DOI: https://doi.org/10.1051/matecconf/201819302032

4. E.N. Degaev, A. Orlov, P.E. Haddad, A. Pleshivtsev, MATEC Web of Conferences 251, 06013 (2018). DOI: https://doi.org/10.1051/matecconf/201825106013

5. E.N. Degaev, A. Suvorova, A. Suhova, IOP Conf. Ser.: Mater. Sci. Eng. 365, 032019 (2018). DOI: https://doi.org/10.1088/1757-899X/365/3/032019

6. E.N. Degaev, V. Razvalyaeva, S. Sabenina, IOP Conf. Ser.: Mater. Sci. Eng. 365 062037 (2018). DOI: https://doi.org/10.1088/1757-899X/365/6/062037

7. E. Degaev, R. Barkhi, J. Phys.: Conf. Ser. 1425, 012066 (2019). DOI: https://doi.org/10.1088/1742-6596/1425/1/012066

8. E. Degaev, E3S Web of Conferences 135, 01008 (2019). DOI: https://doi.org/10.1051/e3sconf/201913501008

9. V. G. Borkovskaya, Applied Mechanics and Materials 467, 287-290 (2013). DOI: 10.4028/www.scientific.net/AMM.467.287

10. V.G. Borkovskaya, Advanced Materials Research 860-863, 3009-3012 (2013). DOI: 10.4028/www.scientific.net/AMR.860-863.3009

11. V.G. Borkovskaya, Applied Mechanics and Materials 475-476, 1703-1706 (2013). DOI: $10.4028 /$ www.scientific.net/AMM.475-476.1703

12. V. Borkovskaya, D. Passmore, MATEC Web of Conf. 193, 05027 (2018). DOI: https://doi.org/10.1051/matecconf/201819305026

13. V.G. Borkovskaya, D. Passmore, Proceeding of the International Science and Technology Conference "FarEastCon-2018” 1, 243-250 (2018). DOI:10.1007/978-3030-15577-3_24

14. V.G. Borkovskaya, MATEC Web of Conferences 251, 06025 (2018). DOI: https://doi.org/10.1051/matecconf/201825106025 
15. V. Rimshin, B. Labudin, V. Morozov, A. Orlov, A. Kazarian, V. Kazaryan, Advances in Intelligent Systems and Computing 983, 867-876 (2019)

16. E. Kuzina, V. Rimshin, Advances in Intelligent Systems and Computing 983, 911-919 (2019)

17. V.G. Borkovskaya, Yu. Korytova, IOP Conference Series: Materials Science and Engineering 661(1), (2019)

18. V.O. Evseev, V.G. Borkovskaya, R. Barkhi, IOP Conf. Series: Journal of Physics: Conf. Series 1425, 012175 (2020). doi:10.1088/1742-6596/1425/1/012175

19. D. Passmore, V.G. Borkovskaya, IOP Conf. Series: Journal of Physics: Conf. Series 1425, 012166 (2020). doi:10.1088/1742-6596/1425/1/012166

20. A. Varlamov, V. Rimshin, S. Tverskoi, E3S Web of Conferences 91, 02046 (2019)

21. E. Kuzina, V. Rimshin, V. Kurbatov, IOP Conference Series: Materials Science and Engineering 463(4), 042009 (2018)

22. A.A. Varlamov, V.I. Rimshin, S.Y. Tverskoi, IOP Conference Series: Materials Science and Engineering 463(2), 022028 (2018)

23. A.A. Varlamov, V.I. Rimshin, S.Y. Tverskoi, IOP Conference Series: Materials Science and Engineering 463(2), 022029 (2018)

24. N.I. Karpenko, V.A. Eryshev, V.I. Rimshin, IOP Conference Series: Materials Science and Engineering 463(3), 032024 (2018)

25. E. Kuzina, V. Rimshin, Advances in Intelligent Systems and Computing 692, 410-416 (2018)

26. E. Kuzina, A. Cherkas, V. Rimshin, IOP Conference Series: Materials Science and Engineering 365(3), 032053 (2018)

27. A.A. Varlamov, V.I. Rimshin, S.Y. Tverskoi, IFAC-PapersOnLine 51(30), 808-811 (2018)

28. A. Cherkas, V. Rimshin, MATEC Web of Conferences 117, 00027 (2017)

29. V.I. Telichenko, V.I. Rimshin, A.V. Karelskii, B.V. Labudin, V.L. Kurbatov, Journal of Industrial Pollution Control, (2017)

30. V.I. Rimshin, E.A. Larionov, V.T. Erofeyev, V.L. Kurbatov, Life Science Journal 11(11), 278-280 (2014) 